\title{
Adolescent Health Care in a Primary Health Unit in Olinda, Brazil
}

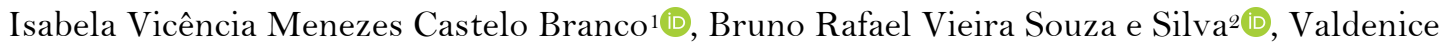 \\ Menezes $^{1}$ (D), Fabiana Godoy ${ }^{1}$ (D), Viviane Colares ${ }^{1}$ (D), Carolina da Franca Bandeira Ferreira Santos ${ }^{1}$ (D)
}

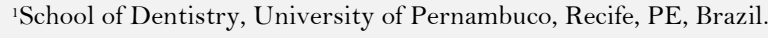

${ }^{2}$ School of Physical Education, University of Pernambuco, Recife, PE, Brazil.

Correspondence: Isabela Vicência Menezes Castelo Branco, Av. General. Newton Cavalcanti, 1650, Tabatinga, Camaragibe, PE, Brazil. 54756-220. E-mail: isabelamcbranco@yahoo.com.br

\section{Academic Editor: Lucianne Cople Maia}

Received: 11 August 2020 / Review: 01 February 2021 / Accepted: 16 March 2021

How to cite: Branco IVMC, Silva BRVS, Menezes V, Godoy F, Colares V, Santos CFBF. Adolescent health care in a
primary health unit in Olinda, Brazil. Pesqui Bras Odontopediatria Clín Integr. $2021 ; \quad 21: e 0182$.
https://doi.org/10.1590/pboci.2021.119
https://doi.org/10.1590/pboci.2021.119

\begin{abstract}
Objective: To characterize adolescent health care in a Family Health Unit in Olinda, Brazil. Material and Methods: The study carried out a census in a primary health unit, and results were obtained through the analysis of medical records from individuals aged 10-19 years. Data analysis was initially performed by descriptive statistics followed by association analysis using the Chi-square test or Fisher's exact test $(\mathrm{p} \leq 0.05)$. Results: Of all registered adolescents $(\mathrm{n}=895), 54 \%$ were female. However, only $36.9 \%(\mathrm{n}=330)$ had a care record from 10 to 19 years. Regarding the frequency with which adolescents used the health service, $89.1 \%$ performed no more than three visits throughout the entire adolescence period. Almost all care provided to adolescents had curative nature (82.7\%) in relation to the preventive nature (17.3\%). Conclusion: The results pointed out that adolescents seek the Family Health Unit predominantly in search of curative care and that the number of consultations is reduced and far from recommendations from the Paced and Integrated Programming Guideline of the Ministry of Health, which establishes a minimum of one medical consultation and two nursing consultations per year for adolescents and young people in general.
\end{abstract}

Keywords: Primary Health Care; Adolescent; Adolescent Health. 


\section{Introduction}

Comprehensive adolescent health care can prevent the onset of health problems and chronic diseases, which negatively interfere in this population's healthy growth and development [1]. The lifestyle adopted by individuals during adolescence will tend to persist in the future and, therefore, is directly related to the development of chronic diseases [2]. Therefore, the World Health Organization (WHO) recommends that adolescents, especially in the age group from 13 to 15 years, have their health risk and protection behavior monitored [3].

Health risk behaviors, especially among adolescents, are closely related to non-communicable diseases. Therefore, these diseases could be avoided through early interventions aimed at preventing risky health behaviors [4], including smoking, physical inactivity, inadequate nutrition, obesity, dyslipidemia, alcohol and illegal drug consumption, and unprotected sexual activity [5].

Primary care is an important strategy for achieving better methods of prevention and care for adolescents and plays a significant role in sustaining the perspective of comprehensive care, as it is the health service most closely linked to the community and should be the preferred contact for users, the main gateway and communication with the entire health care network. In addition, it should favor the development of actions that offer health promotion, disease prevention, treatment, rehabilitation and health status maintenance [6].

According to Costa and Formigli [7], in a study that evaluated 360 medical records of adolescents compared to standards of the Pan American Health Organization/World Health Organization (WHO) and the Ministry of Health, health services have attended the adolescent population with satisfactory level of quality. On the other hand, inadequacy or insufficiency of some aspects denotes the need to reinforce health education actions and retraining of professionals for the clinical care of specific problems in adolescence.

Despite the existence of health policies aimed at the adolescent population, it is clear that there are gaps in practice. Health care does not take place in a systematic way, but according to the spontaneous demand of the unit [8]. In addition, adolescent health problems are most often treated in places designed for adult care without following the guidelines of the main policies aimed at this population [9].

Since late 1980s, there have been resolutions to establish adolescent health care programs, such as the Adolescent Health Program - PROSAD [10]. However, actions aimed at the health of this population are still not being effectively implemented by public policies, which ends up by limiting the service to risk situations, such as infections by sexually transmitted diseases, drug abuse and unwanted pregnancy, distancing from the principles of the Unified Health System (SUS) [11].

It is necessary to understand health in its broader context and managers, health professionals, family and society should understand the health needs of adolescents, as well as the environmental, social and cultural factors that affect their health. These specific characteristics and influences of the context in which they live must also be considered in the planning, development, management and organization of health services [1].

Given the above, this research sought to characterize the adolescent care in a primary health unit, as it is understood that in the context of primary health care, professionals, for being closer to the population, must understand and act on the needs of care to be developed with this age group.

\section{Material and Methods}

Ethical Clearance

This work was approved by the Research Ethics Committee of the UPE under CAAE number 138008 13.7.0000.5207 and by the city hall of Olinda, Pernambuco, Brasil. 


\section{Data Collection}

A census was carried out in a Family Health Unit. Selection took place at random, where a draw was carried out among the 40 family health units in the city and the selected one was invited to participate in the study. Results were obtained through the analysis of the medical records of adolescents of both genders born between 1997 and 2006 for being within the age group of 10 - 19 years during the research period (November to December 2016).

The Health Unit studied is located in a needy community comprising about 1,800 registered families, most of them from low socioeconomic stratum.

\section{Data Analysis}

Statistical analysis was descriptively performed through absolute and relative frequencies with the aid of the GraphPad Prism 5.0 (GraphPad Software, San Diego, CA, USA) and SPSS Statistics 19.0 software (IBM Corp., Armonk, NY, USA), to describe the sample characteristics. For categorical variables, the Chi-square test or Fisher's exact test was used, where p-value $\leq 0.05$ was considered significant.

\section{Results}

Of all registered adolescents $(n=895), 54 \%(n=484)$ were female. However, only $36.9 \%(n=330)$ had a record of care from 10 to 19 years of age. Among the 647 consultations provided to participating adolescents $(n=330)$, the age group of early adolescence (10-14 years old) received a higher number of $68.5 \%$ compared to late adolescence (15-19 years old) with $31.5 \%$, and the largest number of consultations was performed at the age of 10 years. Regarding the frequency with which adolescents $(n=330)$ used the health service, $89.1 \%$ $(\mathrm{n}=294)$ performed no more than 3 visits during the entire adolescence period (Table 1$)$.

Table 1. Frequency of consultations recorded in medical records.

\begin{tabular}{cccccccc}
\hline \multirow{2}{*}{ Frequency of Care } & \multicolumn{2}{c}{ Male } & \multicolumn{2}{c}{ Female } & \multicolumn{2}{c}{ Total } \\
& $\mathrm{N}$ & $\%$ & $\mathrm{~N}$ & $\%$ & $\mathrm{~N}$ & $\%$ \\
\hline$\leq 3$ & 121 & 36.7 & 173 & 52.4 & 294 & 89.1 \\
$4-9$ & 10 & 3.0 & 23 & 7.0 & 33 & 10.0 \\
$>9$ & $\mathrm{O}$ & 0.0 & 3 & 0.9 & 3 & 0.9 \\
\hline
\end{tabular}

No significant difference was observed when variables frequency and sex were associated $(\mathrm{p}=0.1779)$. Almost all care provided to adolescents had curative nature, $82.7 \%(\mathrm{n}=535)$, compared to preventive nature, $17.3 \%(\mathrm{n}=112)$. Most of the 647 consultations with adolescents were carried out by a doctor $(70.7 \%)$; followed by nurse (18.2); psychologist (6.8\%); nutritionist (3.7\%) and care shared between doctor and nurse (0.6\%). Regarding types of care, it was observed that nurses performed more programmatic actions (prenatal care, cervical cancer prevention, family planning) than doctors (Table 2 ).

Table 2. Comparison of demand for care received by doctors and nurses.

\begin{tabular}{lcccccc}
\multicolumn{1}{c}{ Types of Care } & \multicolumn{2}{c}{ Nurse } & \multicolumn{2}{c}{ Doctor } & \multicolumn{2}{c}{ Total } \\
& $\mathrm{N}$ & $\%$ & $\mathrm{~N}$ & $\%$ & $\mathrm{~N}$ & $\%$ \\
\hline General Practice & 19 & 16.1 & 368 & 80.2 & 387 & 67.3 \\
Exams, Referrals* & 10 & 8.5 & 75 & 16.6 & 85 & 14.7 \\
Sexuality and Reproduction & 58 & 49.2 & 12 & 2.8 & 70 & 12.2 \\
Family Planning & 20 & 16.9 & 1 & 0.2 & 21 & 3.7 \\
Cervical Cancer Prevention & 8 & 6.8 & 0 & 0.0 & 8 & 1.4 \\
Prenatal & 3 & 2.5 & 1 & 0.2 & 4 & 0.7 \\
\multicolumn{1}{r}{ Total } & 118 & 100.0 & 457 & 100.0 & 575 & 100.0 \\
\hline *Consultations carried out exclusively to request exams and referrals. & & & &
\end{tabular}


Of the 178 referrals found in medical records, $82 \%$ were performed by the doctor, $11.8 \%$ by the nurse and $6.2 \%$ by the psychologist. Ophthalmology, gynecology and psychiatry are among specialties most referenced by each professional, respectively (Table 3 ).

Table 3. Specialties that received referrals according to the health professional responsible for the care.

\begin{tabular}{lcccccccc}
\multicolumn{1}{c}{ Specialties } & \multicolumn{2}{c}{ Doctor } & \multicolumn{2}{c}{ Nurse } & \multicolumn{2}{c}{ Psychologist } & \multicolumn{2}{c}{ Total } \\
\hline Ophthalmologist & N & $\%$ & $\mathrm{~N}$ & $\%$ & $\mathrm{~N}$ & $\%$ & $\mathrm{~N}$ & $\%$ \\
Dermatologist & 44 & 30.2 & 1 & 4.8 & 0 & 0.0 & 45 & 25.3 \\
Otolaryngologist & 25 & 17.1 & 0 & 0.0 & 0 & 0.0 & 25 & 14.0 \\
Psychiatrist & 14 & 9.6 & 0 & 0.0 & 0 & 0.0 & 14 & 7.8 \\
Psychologist & 5 & 3.4 & 2 & 9.5 & 7 & 63.7 & 14 & 7.8 \\
Gynecologist & 12 & 8.2 & 1 & 4.8 & 0 & 0.0 & 13 & 7.3 \\
Endocrinologist & 4 & 2.7 & 7 & 33.3 & 0 & 0.0 & 11 & 6.2 \\
Nutritionist & 9 & 6.2 & 0 & 0.0 & 0 & 0.0 & 9 & 5.0 \\
Pediatrician & 6 & 4.1 & 1 & 4.8 & 1 & 9.0 & 8 & 4.5 \\
Cardiologist & 3 & 2.0 & 5 & 23.8 & 0 & 0.0 & 8 & 4.5 \\
Neurologist & 5 & 3.4 & 0 & 0.0 & 1 & 9 & 6 & 3.4 \\
Surgeon & 4 & 2.7 & 0 & 0.0 & 2 & 18.3 & 6 & 3.4 \\
General practice & 3 & 2.0 & 1 & 4.8 & 0 & 0.0 & 4 & 2.2 \\
Allergist & 0 & 0.0 & 3 & 14.2 & 0 & 0.0 & 3 & 1.7 \\
Orthopedist & 2 & 1.4 & 0 & 0.0 & 0 & 0.0 & 2 & 1.1 \\
Angiologist & 2 & 1.4 & 0 & 0.0 & 0 & 0.0 & 2 & 1.1 \\
Emergency & 2 & 1.4 & 0 & 0.0 & 0 & 0.0 & 2 & 1.1 \\
Mastologist & 1 & 0.7 & 0 & 0.0 & 0 & 0.0 & 1 & 0.6 \\
Nephrologist & 1 & 0.7 & 0 & 0.0 & 0 & 0.0 & 1 & 0.6 \\
Pulmonologist & 1 & 0.7 & 0 & 0.0 & 0 & 0.0 & 1 & 0.6 \\
Dental surgeon & 1 & 0.7 & 0 & 0.0 & 0 & 0.0 & 1 & 0.6 \\
Urologist & 1 & 0.7 & 0 & 0.0 & 0 & 0.0 & 1 & 0.6 \\
$\quad$ Total & 1 & 0.7 & 0 & 0.0 & 0 & 0.0 & 1 & 0.6 \\
\hline & 146 & 100.0 & 21 & 100.0 & 11 & 100.0 & 178 & 100.0 \\
\hline
\end{tabular}

In only $5.4 \%(\mathrm{n}=35)$ of the medical records of adolescents, there was record that the adolescent attended consultation accompanied by parent / caregiver. Among these, the largest proportion $74.3 \%(\mathrm{n}=26)$ belonged to early adolescence and $25.7 \%(n=9)$ to late adolescence.

Regarding nutritional status, weight and height were recorded, necessary for calculating BMI and evaluating the body mass index in only $6.5 \%(\mathrm{n}=42)$ of the 647 consultations. Among those who were weighed and measured $(\mathrm{n}=42), 73.8 \%$ had abnormal weight status and more than half $(61.9 \%)$ were seen by a doctor and $38.1 \%$ by a nutritionist (Table 4 ).

Considering all participating adolescents $(\mathrm{n}=330)$, there was a record of sexual initiation in $10 \%$ $(\mathrm{n}=33)$, with $21.2 \%(\mathrm{n}=7)$ aged $10-14$ years and $78.8 \%(\mathrm{n}=26)$ aged $15-19$ years, most identified by attending family planning consultations.

Table 4. Nutritional status of adolescents.

\begin{tabular}{|c|c|c|}
\hline Nutritional Status & $\mathbf{N}$ & $\%$ \\
\hline Underweight & 16 & 38.1 \\
\hline Overweight & 12 & 28.6 \\
\hline Normal Weight & 11 & 26.2 \\
\hline Obesity & 3 & 7.1 \\
\hline Total & 42 & 100.0 \\
\hline
\end{tabular}

\section{Discussion}


Regarding gender, the survey revealed that girls sought care 1.5 times more (60.3\%) compared to boys (39.7\%). Some studies point to this difference between genders and report that girls seem to be more concerned about their own health, highlighting the need for care due to motherhood [12-16]. The invisibility of men in the primary care service is associated with heath self-care devaluation typical of this gender and the lack of demand for care, search for self-medication or emergency care services, which makes this gender more focused on curative care than on preventive care [13]. Marcell et al. [14] corroborates the idea of male predominance in emergency departments and reports that the use of clinical health care by male adolescents decreases as they get older, unlike what is observed with females in the same period. In a qualitative study carried out in Rio de Janeiro, community health agents [15] concluded that boys face more difficulty in accessing prevention, treatment and health services when compared to girls, as they have greater flow within Family Health Units (USF) when they report symptoms of sexually transmitted diseases (STD's), as they are examined by the nurse to perform the Pap smear. Women's reproductive issues, including menarche, contraceptives, sexually transmitted diseases (STDs), pregnancy prevention and prenatal care provide important opportunities for women of all ages to establish contact with or engage in health services that are not readily available to men [14].

The age group of early adolescence (10-14 years of age) showed a greater number of consultations $(68.5 \%)$ with the highest number of consultations held at 10 years of age, compared to late adolescence (15-19 years of age). This result draws attention to the fact that it is precisely in the period from 15 to 19 years of age that these individuals are exposed and vulnerable to sexually transmitted diseases, alcohol and drug addiction and unwanted pregnancy.

Regarding the frequency with which adolescents used the Family Health Unit, the majority (89.1\%) performed no more than three visits during adolescence. This result draws attention since of the 895 registered adolescents, only 330 had records of care during the adolescence period and even so, almost all performed no more than three visits to the health unit. It can be observed that two-thirds of adolescents remain outside the health service, and those who attend it, do it in search of a solution to an already installed problem. A minimum of one medical consultation and two nursing consultations per year are recommended for adolescents and young people as a parameter to support health actions as a reference to guide their planning, programming and prioritization [6].

Almost all adolescents $(82.7 \%)$ sought the health unit for curative care in relation to preventive care $(17.3 \%)$. This result corroborates studies by [11-12,15], which demonstrate that the search for health services is motivated by the presence of the disease and associated factors. For Malfitano and Bardi [16], young boys are invisible to the Family Health Strategy unless they have a health problem. Through the result found and compared to literature, it is clear the need for a change in the health focus so that adolescents are cared for in a comprehensive way, as procedures within the sphere of prevention tend not to be considered important, and health services should adopt specific strategies for adolescent care. As an example, a study on vaccination coverage against hepatitis B in adolescents found that $85.3 \%$ of adolescents completed the schedule of the three necessary doses because they received guidance from a health professional on the importance of vaccination [17]. Thus, it is clear the importance of health professionals being aware of this age group's needs to provide comprehensive care for adolescents, including prevention and health promotion.

According to data found in medical records, most of the 647 consultations were carried out by a doctor $(70.7 \%)$, followed by nurse (18.2\%), psychologist (6.8\%), nutritionist (3.7\%) and consultation shared between doctor and nurse (0.6\%). The care provided at the Health Unit under study takes place through spontaneous 
demand, and the health model centered on the medical professional; the other professionals working in the Health Unit are not recognized/ searched. As in the study by Costa et al. [18], when discussing support networks for adolescents, they only highlighted the doctor as a relationship of access to care, and the other Family Health Strategy health professionals were not mentioned. This is a reality that goes against the principles of Primary Health Care, as without the participation of other health team professionals such as dentists, it would not be possible to identify risks, needs and health demands of adolescents. The roles played by health professionals in primary health units need to be highlighted so that they become the support network for those who seek them.

Regarding types of care, it was found that nurses performed more programmatic actions (prenatal care, cervical cancer prevention, family planning) than doctors. In the present study, adolescents' needs showed a homogeneous pattern and were mainly related to sexuality, reproduction and general clinical complaints such as headaches, vision problems, viruses and dermatitis. Clinical complaints were almost always in search of immediate care, need for exams or referral to specialists. On the topic of sexuality, their needs were summarized as the search for condoms, morning-after pills and pregnancy tests. Without specific care, this demand is only fulfilled from the perspective of reproduction and contraception, losing space for discussion of other risk behaviors.

On the other hand, for Higarashi et al. [19], a comprehensive approach to health is unfeasible because adolescent care is restricted to nursing consultations on spontaneous demand. This statement corroborates the results of this research, where most complaints related to sexuality and reproduction were received in consultations with a nurse $(49.2 \%)$. It should be highlighted the need for nurses within the primary health unit to act beyond care related to reproduction. Receiving adolescents and facilitating access by this professional favors the formation of a bond between professional and patient, which can open space for discussion of risk behaviors related to other fields of adolescent health, such as drug use, physical activity, healthy food habits, body weight, among others.

Of the 178 referrals found in medical records, $82 \%$ were made by the doctor, $11.8 \%$ by the nurse and $6.2 \%$ by the psychologist. Ophthalmology, gynecology and psychiatry are among the specialties most referenced by each professional, respectively. When comparing the number of consultations with complaints related to sexuality and reproduction $(n=70)$, with referrals to specialties gynecology $(n=11)$ and urology $(\mathrm{n}=1)$, it is evident that a considerable number of adolescents are without specific care. According to the Basic Guidelines for Comprehensive Health Care for Adolescents in Schools and Primary Health Units [20], girls who have already started sexual activities or not and who have a gynecological problem should be referred for gynecological examination. In addition, concerning male adolescents who have or have not started sexual activities, the need for referral should be assessed if they present any genitourinary problem. Marques and Queiroz [21] reveal that the absence of organizational elements impairs referral and solving population's problems. In some medical records of the present study, it was observed that it was not possible to make an appointment with the specialist, or after referral, there was no return for reassessment. This gap was observed in some medical records, not representing expressive frequency.

In only $5.4 \%(n=35)$ of medical records of attended adolescents, there was record that the adolescent attended the consultation accompanied by parent / caregiver. Among these, the largest proportion $74.3 \%$ $(\mathrm{n}=26)$ belonged to early adolescence and $25.7 \%(\mathrm{n}=9)$ to late adolescence. This result is positive and agrees with the approach recommended in the Basic Guidelines for Comprehensive Health Care for Adolescents in Schools and Basic Health Units [20] because, when adolescents seek the primary health unit without being 
accompanied by parent / caregiver, he/she has the right to be attended to alone. This moment is very important and qualified listening should be advocated, providing free expression without many questions or judgments. Clarification is needed for these adolescents about the health-disease process and ways of preventing health problems to favor greater autonomy for adolescents in relation to their own health.

Regarding nutritional status, weight and height were recorded, necessary for calculating BMI and evaluating the body mass index in only $6.5 \%(\mathrm{n}=42)$ of the 647 consultations. Among those who were weighed and measured $(n=42), 73.8 \%$ had abnormal weight status and more than half $(61.9 \%)$ were seen by a doctor and $38.1 \%$ by a nutritionist. According to BMI, 38.1\% of adolescents were underweight, $28.6 \%$ overweight and $7 \%$ obese. Only a few population-based studies have assessed the body fat percentage of Brazilian adolescents using more accurate methods, which makes comparisons difficult.

The percentage of underweight adolescents was higher than that reported in a study with adolescents from São Luís, Brazil [22]. The prevalence of obesity (assessed by BMI) was close to that observed for the Northeastern region and lower than that observed nationwide [23]. However, the result found is much lower compared to the number of adolescents attended, who are unmonitored and, therefore, at increased risk.

It is recommended that during physical examination, weight, height, BMI/age and height/age should be assessed according to curves and criteria of the World Health Organization [20]. Furthermore, the study by Silva et al. [24] highlights that intervention and early identification of nutritional alterations depend on the involvement of all health professionals and schools and families. In this regard, primary care in the early detection and follow-up of cases is of paramount importance. In addition, blood pressure measurement should also be performed once a year using BP curves for age [20], which was not found in medical records.

Considering all participating adolescents $(n=330)$, sexual initiation was recorded for $10 \%(n=33)$ of them, $21.2 \%(n=7)$ in the age group of $10-14$ years and $78.8 \%(n=26)$ in the age group of $15-19$ years. Most of these sexually active adolescents were identified by attending family planning appointments. According to [25], in the age group of 10-14 years, pregnancy is mostly related to the occurrence of sexual violence. In the more advanced ages of adolescence, from 15 to 19 years of age, pregnancy tends to be related to lack of information, guidance/education in sexuality; restrictions on access to health services and supplies for reproductive planning, as well as the low status of female adolescents in society.

Two public schools are included in the coverage area of the health, but health activities involving schools were not developed at the time the study was conducted, which is an important gap, since young people are exposed to risk factors. If health services and schools do not present themselves as a support network, adolescents will not perceive them as a reference in the search for guidance.

The classic model of clinical anamnesis is inadequate for adolescent care in primary health care, as social, sexual, psychological aspects, possible situations of vulnerability or risk for violence, abuse of alcohol and drugs, among others, are not considered [20]. Also, according to these guidelines, the moment after appointment should be used to clarify possible doubts about the use of condoms (male and female), contraceptive methods, in addition to explaining the adverse effects of alcohol, tobacco and other drug abuse. Nevertheless, no record was found in medical records about the use and frequency of intake of these substances by adolescents and, therefore, the service is not fulfilling the function [25] of identifying health risks, needs and demands. The National Primary Health Care Policy (Política Nacional de Atenção Básica) [26] highlights the relevance of primary care actions in detecting the initial use of drugs by adolescents, since the Family Health Strategy must act by identifying demands in the context of its territories, allowing health professionals to monitor and help adolescents in their health needs. 
The limitations of this work include the unique nature of the sample (one health unit) and, in addition, all information used was taken from paper records, handwritten by health professionals without any type of standardization. Thus, it emphasizes the importance of filling out medical records as completely as possible to know the real health situation of adolescents and provide adequate care [27].

\section{Conclusion}

The clinical approach to adolescents needs to align with the Basic Guidelines for Comprehensive Health Care for Adolescents in Schools and Basic Health Units, as important gaps were found in medical records. The classic model of clinical anamnesis is inadequate for adolescent care in primary health care because sociocultural and psychological aspects of vulnerability to exposure to risks such as alcohol, drugs and violence are not considered. This study points to the need for the implementation of some changes in the panorama of care provided to adolescents in the context of primary health care, and it is expected that it will promote reflections on the need to improve care in this population, starting in the primary health unit to reach the principles of integrality.

\section{Authors' Contributions}

\begin{tabular}{|c|c|c|}
\hline IVMCB (iD) & https://orcid.org/0000-0001-6269-1570 & Data Curation, Writing - Original Draft and Writing - Review and Editing. \\
\hline BRVSS (iD) & https://orcid.org/0000-0002-6140-6990 & Writing - Review and Editing, Visualization and Supervision. \\
\hline VM & https://orcid.org/0000-0003-4183-3239 & Writing - Review and Editing, Visualization and Supervision. \\
\hline FG & https://orcid.org/0000-0002-1946-9605 & Writing - Review and Editing, Visualization and Supervision. \\
\hline $\mathrm{VC}$ & https://orcid.org/0000-0003-2912-2100 & Conceptualization, Methodology and Writing - Review and Editing \\
\hline CFBFS (iD) & https://orcid.org/0000-0002-7365-2806 & $\begin{array}{l}\text { Conceptualization, Methodology, Formal Analysis, Investigation and Writing - Review and } \\
\text { Editing }\end{array}$ \\
\hline
\end{tabular}

\section{Financial Support}

None.

\section{Conflict of Interest}

The authors declare no conflicts of interest.

\section{Data Availability}

The data used to support the findings of this study can be made available upon request to the corresponding author.

\section{References}

[1] Brasil. Ministério da Saúde. Secretaria de Atenção em Saúde. Departamento de Ações Programáticas Estratégicas. Diretrizes Nacionais Para a Atenção Integral à Saúde de Adolescentes e Jovens na Promoção, Proteção e Recuperação da Saúde. Brasília: Ministério da Saúde; 2010. [In Portuguese].

[Q] Brasil. Ministério do Planejamento, Orçamento e Gestão. Instituto Brasileiro de Geografia e Estatística - IBGE. Diretoria de Pesquisas Coordenação de População e Indicadores Sociais. Pesquisa Nacional de Saúde do EscolarPENSE 2009. Rio de Janeiro: IBGE; 2009. [In Portuguese].

[3] Centers for Disease Control and Prevention. Global School-Based Student Health Survey (GSHS). Available from: https://www.cdc.gov/gshs/index.htm [Accessed on March 18, 2020].

[4] Malta DC, Cezário AC, Moura L, Morais Neto OL, Silva JJB. Building surveillance and prevention for chronic non communicable diseases in the national Unified Health System. Epidemiol Serv Saúde 2006; 15(3):47-65. https://doi.org/10.5123/S1679-49742006000300006

[5] Patton G, Coffey C, Cappa C, Currie D, Riley L, Gore F, et al. Health of the world's adolescents: A synthesis of internationally comparable data. Lancet 2012; 379(9826):1665-75. https://doi.org/10.1016/So140-6736(12)60203-7

[6] Brasil. Ministério da Saúde. Secretaria de Atenção à Saúde. Departamento de Regulação, Avaliação e Controle de Sistemas. Diretrizes Para a Programação Pactuada e Integrada da Assistência à Saúde. Brasília: Ministério da Saúde; 2006. [In Portuguese]. 
[7] Costa MCO, Formigli VLA. Quality evaluation of health care service for adolescents. Rev Saúde Pública 2001; 35(2):177-84. https://doi.org/10.1590/So034-89102001000200012

[8] Ferrari RAP, Thomson Z, Melchior R. Healthcare for adolescents: perceptions by physicians and nurses in family health teams. Cad Saúde Pública 2006; 22(11):2491-5. https://doi.org/10.1590/So 102-311X2006001 100024

[9] Raupp L, Milnitsky-Sapiro C. Adolescence, drug-addiction and public policies: contemporary scenarios. Estud Psicol 2009; 26(4):445-54. https://doi.org/10.1590/S0103-166X2009000400005

[10] Brasil. Ministério da Saúde. Secretaria Executiva. Coordenação da Saúde da Criança e do Adolescente. Programa Saúde do Adolescente. Bases Programáticas. 2nd. ed. Brasília: Ministério da Saúde; 1996. 32p. [In Portuguese].

[11] Vieira RP, Gomes SHP, Machado MFAS, Bezerra IMP, Machado CA. Healthcare and the demand for services in the family health strategy: the perspective of adolescents. Cogitare Enferm 2014; 22(2):309-16. https://doi.org/10.1590/0104-1169.3182.2417

[12] Ayres JRCM, Carvalho YM, Nasser MA, Saltão RM, Mendes VM. Ways of comprehensiveness: adolescentes and young adults in Primary Healthcare. Interface 2012; 16(40):67-82. https://doi.org/10.1590/S1414-3283201200500002 1

[13] Figueiredo W. Assistance to the men health: a challenge for the services of primary attention. Ciênc Saúde Coletiva 2005; 10(1):105-9. https://doi.org/10.1590/S1413-81232005000100017

[14] Marcell AV, Klein JD, Fischer I, Allan MJ, Kokotailo PK. Male adolescent use of health care services: where are the boys? J Adolesc Health 2002; 30(1):35-43. https://doi.org/10.1016/s 1054-139x(01)00319-6

[15] Bellenzani R, Santos AO, Paiva V. Community health agents and care provided for youths' sexual and reproductive health in the family health strategy. Saude Soc 2012; $11(3): 637-50$.

https://doi.org/10.1590/So 104-12902012000300010

[16] Malfitano APS, Bardi G. Primary health care and youth: between old dilemmas and new challenges. Rev Bras Ciênc Saúde 2014; 18(2):137-46.

[17] Francisco PMSB, Donalisio MR, Gabriel FJO, Barros MBA. Hepatitis B vaccination in adolescents living in Campinas, São Paulo, Brazil. Rev Bras Epidemiol 2015; 18(3):552-67.

https://doi.org/10.1590/1980-5497201500030003

[18] Costa RFZ, Regina CG, Queiroz MVO, Gómez GCI, Ruiz GMJ. Adolescent support networks in a health care context: the interface between health, family and education. Rev Esc Enferm 2015; 49(5):741-7. https://doi.org/10.1590/S0080-623420150000500005

[19] Higarashi IH, Baratieri T, Roecker S, Marcon SS. Nurses' work with adolescents: identifying difficulties and prospects for changeRev Enferm UERJ 2011; 19(3):375-80.

[20] Brasil. Ministério da Saúde. Secretaria de Atenção à Saúde. Departamento de Ações Programáticas Estratégicas. Orientações Básicas de Atenção Integral à Saúde de Adolescentes nas Escolas e Unidades Básicas de Saúde. Brasília: Ministério da Saúde; 2013. [In Portuguese].

[21] Marques JF, Queiroz MVO. Adolescent treatment in primary care: needs of patients and their relations with service. Rev Gaúcha Enferm 2012; 33(3):65-72. https://doi.org/10.1590/S1983-14472012000300009

[22] Simões VMF, Batista RFL, Alves MTSSB, Ribeiro CCC, Thomaz EBAF, Carvalho CA, et al. Health of adolescents in the 1997/1998 birth cohort in São Luís, Maranhão State, Brazil. Cad Saúde Pública 2020; 36(7):e00164519. https://doi.org/10.1590/0102-311 x00164519.

[23] Bloch KV, Klein CH, Szklo M, Kuschnir MCC, Abreu GA, Barufaldi LA, et al. ERICA: prevalences of hypertension and obesity in Brazilian adolescents. Rev Saúde Pública 2016; 50(Suppl 1):9s.

https://doi.org/10.1590/s01518-8787.2016050006685

[24] Silva F, Ferreira E, Gonçalves R, Cavaco A. Pediatric obesity: the reality of one consultation. Acta Med Port 2012; 25(2):91-6.

[25] Brasil. Ministério da Saúde. Secretaria de Atenção à Saúde. O SUS e a Saúde Sexual e Reprodutiva de Adolescentes e Jovens no Brasil. Brasília: Ministério da Saúde; 2013. [In Portuguese].

[26] Brasil. Ministério da Saúde. Secretaria de Atenção à Saúde. Departamento de Atenção Básica. Política Nacional de Atenção Básica. Brasília: Ministério da Saúde; 2012. [In Portuguese].

[27] Rosa WAG, Labate RC. Family health program: the construction of a new care model. Rev Latino-Am Enfermagem 2005; 13(6):1027-34. https://doi.org/10.1590/So 104-11692005000600016 